\title{
Review articles required for inclusion in Index Medicus and Medline
}

\author{
Junichi Asaumi ${ }^{1}$
}

Published online: 22 April 2016

(C) Japanese Society for Oral and Maxillofacial Radiology and Springer Japan 2016

\section{Dear Readers}

I am very proud to announce that I am now the fourth Editor-in-Chief of Oral Radiology $(O R)$. I replace the third editor of $O R$, Professor Keiji Tanimoto of Hiroshima University.

$O R$ was first published in 1985. The first editor of $O R$, Professor Hajime Fuchihata of Osaka University, published two issues of $O R$. In 1992, Professor Kanji Kishi of Okayama University became the Editor-in-Chief, beginning with volume 8 , number 2 . In 2002, beginning with volume 18, number 1, Professor Tanimoto took over the position. Professor Tanimoto contributed to the development of $O R$ for 13 years. I succeeded him in 2016, beginning with volume 32, number 1 .

$O R$ is an English language journal published and supported by the Japanese Society for Oral and Maxillofacial Radiology. $O R$ has been distributed worldwide as a result of our collaboration with the international publisher, Springer-Verlag. Since 2008, $O R$ has been indexed in Science Citation Index Expanded. I believe that $O R$ has now become a well-recognized international journal in the field of oral and maxillofacial radiology. We now aim to expand the journal's international scope and intend to apply for inclusion in Index Medicus and Medline.

For inclusion in Index Medicus and Medline, we have to improve the quality of publication in all subjects, particularly review articles. We hope that you will cooperate in preparing your articles, especially review articles.
Our Associate Editors are: Allan G Farman, University of Louisville School of Dentistry; Takafumi Hayashi, Niigata University; Reinhilde Jacobs, Katholieke Universiteit; Yasuhiro Morimoto, Kyushu Dental College; Kaan Orhan, Near East University; Jie Yang, Temple University; and David MacDonald-Jankowski, The University of British Columbia. The current members of the International Editorial Boards are: Jinwu Chen, The Fourth Military Medical School; Yuk-Kwan Chen, Kaohsiung Medical University; Soon-Chul Choi, Seoul National University; Wichitsak Cholitgul, Chulalongkorn University; Malcolm I Coombs, Sydney Dental Hospital; Tazuko K Goto, Tokyo Dental College; Naoya Kakimoto, Osaka University; Sunali Khanna, Nair Hospital Dental College; Eun-Kyung Kim, Dankook University College of Dentistry; Saulo Leonardo Sousa Melo, University of Iowa; Gerard $\mathrm{CH}$ Sanderink, Academic Center for Dentistry; Dania Tamimi, Orlando; Hiroshi Watanabe, Tokyo Medical and Dental University; Ann Wenzel, Aarhus University; and Yoshinobu Yanagi, Okayama University Hospital.

I hope that our journal will further develop and publish breakthroughs in the field as a truly international journal of high quality. I am eager for Oral Radiology to become a worthy source of pride for our society.

Junichi Asaumi

Editor-in-Chief, Oral Radiology

Springer

Junichi Asaumi

asaumi@md.okayama-u.ac.jp

1 Okayama University, Okayama, Japan 